\title{
Management of Conflict in Non-Profit Organization with Shared Governance
}

\author{
Alexis Louis Roy, Christelle Perrin, Christophe Assens \\ Université Paris-Saclay, UVSQ, Larequoi, Versailles, France \\ Email: christophe.assens@uvsq.fr
}

How to cite this paper: Roy, A. L., Perrin, C., \& Assens, C. (2022). Management of Conflict in Non-Profit Organization with Shared Governance. Open Journal of Social Sciences, 10, 440-457.

https://doi.org/10.4236/jss.2022.101033

Received: December 14, 2021

Accepted: January 24, 2022

Published: January 27, 2022

Copyright $\odot 2022$ by author(s) and Scientific Research Publishing Inc. This work is licensed under the Creative Commons Attribution International License (CC BY 4.0).

http://creativecommons.org/licenses/by/4.0/

(c) (i) Open Access

\begin{abstract}
In social and non-profit organisations with partnership governance, conflicts are more numerous and more difficult to mitigate. Ostrom's organisational principles guarantee the stabilisation of such organisations, but we lack studies about ways to restore their stability after a conflict crisis. Based on Rahim's works on conflict handling styles' influence over long-lasting collaborations, we hypothesize a linkage between Ostrom's organisational principles and effective conflict handling styles. Our article explores this topic from action research based on the comparison of three non-profit organizations: an associative school, a Non-Governmental-Organization, a Think Tank, Each organisation is characterized respectively by three conflict handling styles that can each lead to their collapse. The rules of collegial governance exemplify well, in the three cases studied, as variables that directly affect the modes of conflict resolution of its members. This analysis opens up new avenues of action for conflict management, whereby stabilization is achieved, by changing its collective rules to move towards more collegiality in decision-making.
\end{abstract}

\section{Keywords}

Conflict, Ostrom, Governance, Collegiality, Rules, Partnership

\section{Introduction}

Conflict is a part of the business paradigm because of possible mismatches between individual issues and the collective interest, or individual interpretations of the collective interest (Lubell et al., 2019). The role of management is, traditionally, to reduce this mismatch to align individual and collective issues (Teague \& Roche, 2012). If this discrepancy is not reduced, conflicts may arise between individuals or vis-à-vis the collective, and lead to dysfunction, blockages and disengagement (Ury, Brett, \& Goldberg, 1988). In traditional hierarchical 
structures, authority is a factor in the regulation and arbitration of conflicts (van de Vliert, Euwema, \& Huismans, 1995). In organisations with partnership governance, which are based on co-ownership and the sharing of wealth between the collaborators and sometimes the beneficiaries of the organisation, as in the social and solidarity economy sector, power is no longer vertical, but horizontal and shared. Conflicts are often more numerous and more difficult to mitigate. They are inherent to the life of organisations and are not always a source of dysfunction, provided partnership governance can stabilize and keep internal conflict to a moderate level.

In partnership-based governance, the collective dimension takes precedence and the traditional dispute mediation approaches available to practitioners, in a unitary governance framework (Mayer, 2000; Masters, \& Albright, 2002), prove to be insufficient to manage conflicts. We wish to study how adapted conflict management, at the level of collegiality rules, can restore the long-term stability of an organisation with partnership governance.

According to Ostrom (2010), the collective of individuals participating in partnership governance can, and must, effectively exploit operational conflicts to change its collective rules or to even create a new set of collective rules in line with eight principles of organisational design. Elinor Ostrom shows that these organisational principles are in place in stable organisations with partnership governance, but does not, however, provide any particular conflict resolution protocols to restore the stability of this type of organization nor to implement the organizational principles. Turning to Rahim's (1983) theory of conflict management, we have valuable insights into the most effective conflict handling styles (compromise and integration) for managing conflict between two individuals, but we lack avenues for moving an entire organization, as a whole, from an ineffective Rahim style (dominating, accommodating, avoiding) to an effective conflict handling style.

In this paper, we wish to explore the relationship between Ostrom's (2010) principles of design and organisation, and Rahim's (1983) styles of conflict handling. In particular, we identify one of Ostrom's eight principles that regulate collegial governance and particularly influence Rahim's conflict handling style. This analysis of the links between the two theoretical frameworks opens up new avenues of action for conflict management practitioners (Teague et al., 2015; Galman et al., 2021), whereby the stabilization of an organization with partnership governance, threatened by its internal conflicts, is achieved by changing its collective rules to move towards more collegiality in decision-making.

Our article explores this topic based on three cases of organizations with partnership governance characterized respectively by three of Rahim's conflict handling styles that can each lead to the collapse of these organizations: a conflict handling style by domination, a conflict handling style by accommodation and finally, a conflict handling style by avoidance. To reveal the articulation between the conflicts observed at the individual level and the collective rules in place, we set up a tool to spot a conflict's evolution called, the "Conflict Atlas", 
to identify and categorize the conflicts and the actors' opinions on the rules of collegiality within the organization. A conflict intensity measurement tool is then deployed in order to measure the evolution of conflictuality in each organization according to the actions chosen by the researchers engaged in action research. Finally, an observation of each organization over a period of two to five years, monitors the stabilization of the organizations and identifies a few Ostrom principles among the height principles that greatly influence the change of a conflict handling style.

In order to clarify the paper's logic, we introduce the structure of the article which is developed in four parts: the review of the literature, the method of data collection, the analysis of the case studies and the research result related to scientific discussion.

\section{Part 1: Literature Review}

\subsection{Conflicts and Partnership Governance: E. Ostrom}

In organisations with partnership governance, conflicts are numerous and difficult to regulate. They are part of the fabric of organisations (Coule, 2015) and are not always a source of dysfunction, provided that they return to a stable state and maintain internal conflict at a moderate level. Alternatively, because each stakeholder has as much legitimacy as the others to support his or her point of view in a governance debate, a possible conflict can lead to the disappearance of the organization (Hardin, 1968; Ostrom, 1990: p. 194).

In the field of shared access to natural resources, Ostrom (2010) was able to identify the link between the collective rules in place within governance and the situations of action. In this analytical framework, interactions between stakeholders are modulated by the rules in place and they have the capacity, in turn, on the basis of the consequences of their interactions, to modify these rules (see Figure 1). Her work was then extended to the field of for-profit and non-profit organisations (Bommier \& Renouard, 2018). Collective rules limit the choices of actors, regulate the sharing of benefits or can determine the sanctions applicable within the partnership governance organisation. Depending on the intensity of the norm (Chatman \& O'Reilly III, 2016), these rules will guide the modalities of interactions. Ostrom (1990) has shown that eight guiding principles are sufficient to set up rules that stabilise an organisation with partnership governance on a long-term basis. To validate the relevance of these principles, Ostrom (1990: p. 194) observed the lifespan of several organizations in the management of common goods and was able to predict which of them could disappear and which of them, because they applied more principles, were likely to prevail in the long term. In particular, she observed the very high vulnerability of these organizations to two principles specifically related to collegial governance: the principle of being able to define collective rules collegially and the principle of distributing costs in proportion to the benefits that each member receives from the organization. 
Table 1. Collegial governance rules as variables directly affecting the elements of "Action situations" and the "Interactions".

\begin{tabular}{ll} 
Style & Description \\
\hline Integrating & $\begin{array}{l}\text { This style aims to seek openness, the search for differences, and the exchange of information to identify a solu- } \\
\text { tion to the conflict. Attention to conflict resolution is at the heart of the resolution process. }\end{array}$ \\
Compromising & $\begin{array}{l}\text { This style corresponds to an attitude of negotiation or sharing the object of the conflict with the other } \\
\text { stakeholders. Negotiation progresses as each stakeholder makes concessions in the conflict. }\end{array}$ \\
Accommodating & $\begin{array}{l}\text { In this style, the party in conflict will try to minimize differences, highlighting communities of interest in order } \\
\text { to seek a solution to the conflict by giving the other party the right to the claims of the other party. }\end{array}$ \\
Dominating & $\begin{array}{l}\text { This behaviour can be likened to a win-lose relationship or a style of conflict management by forcing. The } \\
\text { relationship with the opponent is direct. } \\
\text { This style corresponds to the voluntary exclusion from the conflict or even ignorance of the existence of a } \\
\text { conflict. } \\
\text { This style corresponds to an attitude of separation of an actor from the partnership governance. The break in } \\
\text { collaboration can be completed by the creation of a similar activity, for instance, in a distinct geographical area. }\end{array}$ \\
Breaking &
\end{tabular}

Source: Adapted by the authors from the research of Ostrom (2010).

\subsection{Conflict Management Styles: Rahim}

Debates (which are a subset of what Ostrom (2010) calls "Actions situations", see Figure 1) are discussions or a set of discussions on a specific or substantive topic involving individuals with more or less divergent opinions, ideas, thoughts, and views on a situation. Debates will evolve into conflicts when the interests of one stakeholder are negatively affected by another stakeholder (Wall \& Callister, 1995).

In the context of unitary governance where conflicting stakeholders are not empowered to act on collective rules, many studies on conflict management are based on the theory of Blake \& Mouton (1964), supplemented by the conflict handling styles of Rahim (1983). These theories consider that the interactions between two individuals in conflict can be analysed mainly through psychological factors by confronting the concern for self and the concern for others. The intersection of these two factors draws a set of five conflict handling styles (see Table 1 and Figure 2): avoiding, accommodating, dominating, compromising or integrating.

This set of styles can then be extended to incorporate a sixth attitude: the breaking between stakeholders, which remains a possible option in organisations with partnership governance.

On the basis of this classification of conflict handling styles, other researchers conducted studies on the most effective styles (van de Vliert, Euwema, \& Huismans, 1995). Management styles based on compromise and integration have proven to be the most effective strategies for managing conflict over time. According to this grid, managers are therefore invited to address direct confrontations between the conflicting parties and to develop individual attitudes favouring compromise and even integration. 


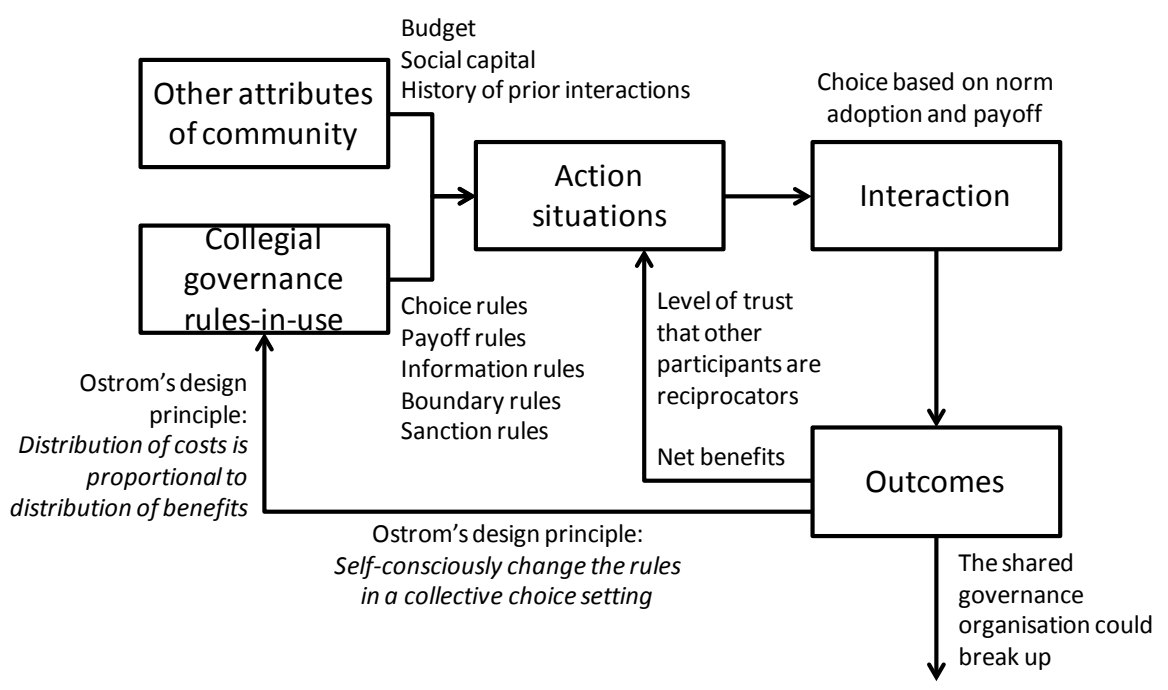

Figure 1. Description of the conflict handling styles of Rahim and the breaking style.

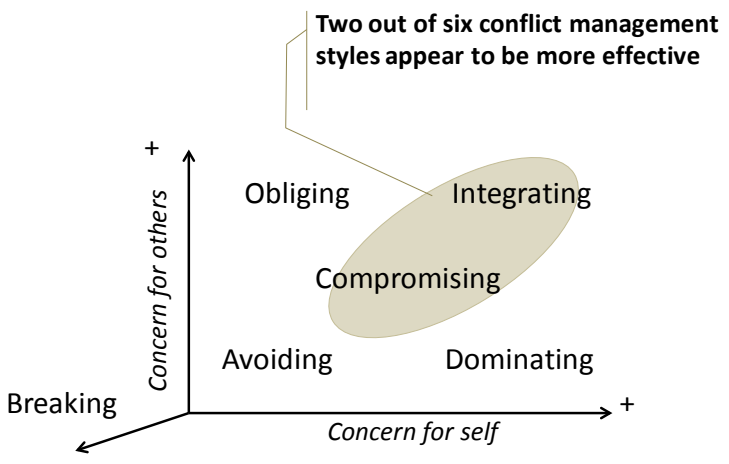

Figure 2. The five styles of interpersonal conflict management. Source: Adapted by the authors from the research of Rahim (1983).

\subsection{The Theoretical Grid: Conflict Management by Rahim and Ostrom}

Rahim's (1983) framework emphasizes that the search for compromise in conflicts gives organizations the most stability; on the other hand, Ostrom's framework emphasizes that the instability of an organization with partnership governance comes from the absence of one or several designing rule principles. The combination of these two works allows us to formulate three theoretical consequences on the link between conflict handling styles and the stability of organisations with partnership governance:

1) The use of a sub-optimal conflict handling style (accommodating, dominating, avoiding or breaking) can lead to the organization's disappearance;

2) Individual dispute resolution is not sufficient to remove the risk of disruption when the mediation is ineffective in imposing a high intensity conflict handling group norm;

3) It is necessary to identify collective rules that will lead to the emergence of an organizational norm favouring conflict management through compromise, or even integration. 
In order to better understand the links between the rules of collegial governance and conflict handling styles, it seemed relevant to us to propose an integration of the two analytical frameworks in a common model (see Figure 3) in which Rahim's style is represented as a path of interaction during conflict. In this model, the style used by the dyad in conflict is influenced by the rules of governance in place. The negative consequences of the conflicts in place will possibly change the rules of governance and norms.

The link between the frameworks of Rahim (1983) and Ostrom (2010) have not been explored or used by conflict management researchers. This observation leads us to formulate the following research questions: are collegial rules a way to durably resolve internal conflicts in an organisation with partnership governance? Can collegial rule change a conflict handling style described as ineffective by Rahim (accommodating, dominating, avoiding)? To investigate these research questions, we compare three case studies of an associative school, a non-governmental organisation (NGO) and a Think Tank.

\section{Part 2: Methods for Data Collection}

\subsection{Research Methodology}

In an attempt to identify a link between conflict and collective rules, we are developing an experimental protocol and measurement tools to access markers of both conflict and shared norms within an organization. The experimental protocol we have chosen is twofold: it combines Eisenhardt's (1989) method of comparative case studies with action research.

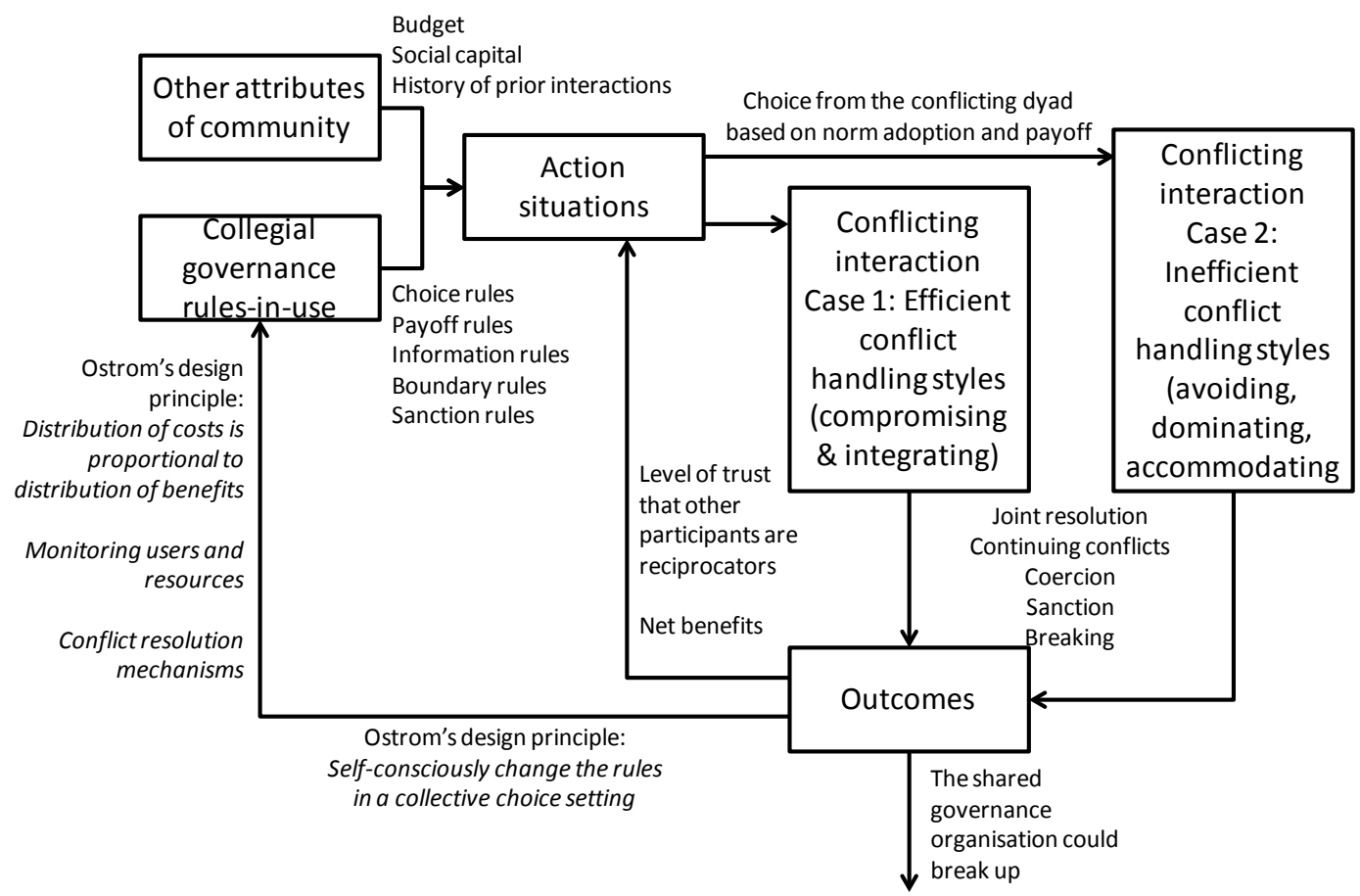

Figure 3. Cross analysis of Rahim's conflict handling styles within E. Ostrom's framework. Source: Assumptions by the authors from the literature review. 
In order to study the link between conflicts and governance rules, we had to consider organisations with partnership governance which, at the beginning of the observation period, shared several common points: comparable size, several ongoing conflicts, location in the same country in order to neutralise the dimension of national culture which could hinder our analysis of shared standards, a size reduced to 40 employees and a location on a single site in order to benefit from a homogeneous organisational culture per case. Each of these organizations had to be identifiable by different Rahim conflict handling styles and activities. This double diversity of cases makes it possible (1), to study a variety of situations in terms of conflict management styles because of its theoretical interest and (2), to improve the generalisation of the results induced by the study by cross-referencing a diversity of activities.

The production of knowledge on the basis of these three cases becomes possible if, first of all, the research question is testable in the field, and if the conditions of intervention, data collection and protocols are homogeneous between the cases. The studies carried out must therefore share a common methodological framework.

\subsection{Action Research Strategies}

The research team followed two action strategies to reduce conflict within the organizations studied. The first strategy consisted in initiating mediation in the event of conflict between two or more members. A second strategy consisted in setting up collegial decision-making or resource-sharing procedures (see Figure 4).

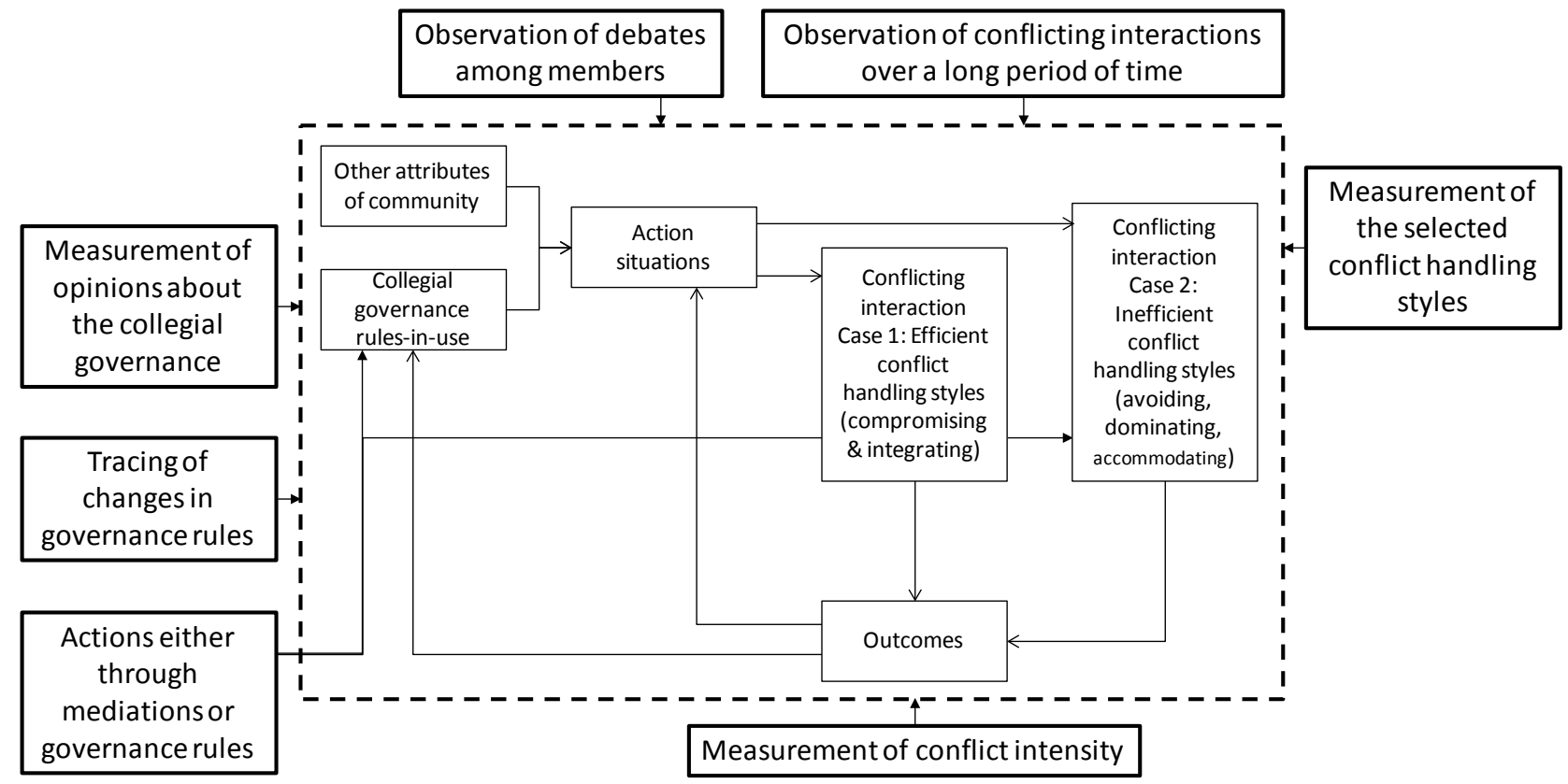

Figure 4. Points of actions and points of measurements of the linkage between governance rules-in-use and conflict handling style. Source: design of this research by the authors. 
In order to reduce the bias related to the presence of researchers and to diminish other factors that could influence the resolution of ongoing conflicts, we instituted the protocol of spacing each action cycle by several months, while continuing to collect data over the entire period. In doing so, we could compare the average conflict intensity between each observation period to justify a link between the action taken at the beginning of the observation period and the conflict observed over the entire period.

\subsection{Selection of the Three Organisations Studied}

We analyzed the organizational culture of height different associations and selected three of them in our study that had three complementary conflict handling styles. These three organisations with partnership governance were the sponsors of the intervention and wished to consolidate their governance in the face of a series of conflicts threatening to disrupt, or even eliminate the organisation (see Table 3):

1) An associative school whose members follow the collective rules but show a strong altruism. The staff of this organization adopts an accommodating conflict handling style at the beginning of the study.

2) An NGO whose members show a strong assertion of their own interest and do not wish to follow collective rules. The staff of this organisation adopts a dominating conflict handling style at the beginning of the study.

3) A Think Tank whose members show little involvement in governance. The staff of this organization adopts a mix of avoiding and accommodating conflict handling styles at the beginning of the study.

\subsection{Data Collection}

We conducted the three separate data collections in each case over a period of two to five years. In each case, we began the analysis by interviewing approximately one-third of the staff in each organization in order to assess the predominant conflict handling style within each organization and to capture ongoing debates and conflicts at the start of the study. During the second phase, we conducted action-research and collected, in parallel with our interventions, the reactions of the actors to the ongoing conflicts and their opinions on the functioning and management of their organisation. We had access to members of the Board of Directors, managers, employees and their elected representatives. We collected roughly 500 pages of documents and conducted over 100 interviews. This mass of data enabled us to understand the contexts in which conflict arose, the evolution of conflicts, the conflict handling styles in each of the three organisations, and to learn the opinions or reflections of their authors on the governance (see Figure 4).

\subsection{Observing Conflict Dynamics through the Conflict Atlas Tool}

Latour's atlas of controversies method (Venturini et al., 2015), initially devel- 
oped in political science debate analysis, has given us useful insights to navigate and analyze a large body of material, actors, opinions, debates, and coalitions. An analytical tool has been specifically developed to observe conflict dynamics in organizations: the conflict atlas. The conflict atlas is a tool based on a database of actors, quotes, conflict intensities, and individual opinions about statements. The atlas allows the researcher to navigate through hundreds of quotes per case, filter them by time period, by actors, by debate, etc. and to visualise counts of conflict intensity or counts of positive or negative opinions, and to cross-check several factors on a graph. These maps, i.e. these graphical representations, build a "conflict atlas".

In an organization, debates emerge in multiple conversations, mixing ethical, economic or governing issues. Some debates are fundamental questions that run through an organization, and to which stakeholders consciously or unconsciously seek answers (i.e. How to reduce overload? Who should succeed the current CEO?). Measuring the importance of each debate helps the governance team and the research team to decide on actions based on collective rules.

We have carried out a coding and a naming of our material according to several aspects. A quote from a document was associated with an author and a date, but also with: 1) a discussion about the organization; 2) a measure of the intensity of conflict in the citation; 3 ) the author's opinion concerning the organization.

Starting from the definition of conflict ("Workplace conflict refers to, a process in which one party perceives its interests to be opposed or negatively affected by another party's", (Wall \& Callister, 1995: p. 517), and making a distinction between the perception of a situation of opposition, on the one hand, and the emotional intensity expressed on the other (De Dreu, 2008), we coded the conflict intensity of a quote as the sum of two values:

1) The author of the quote perceives his or her interests to be thwarted or adversely affected by the interests of another party (on a scale ranging from 1 to 5).

2) The author of the quote demonstrates high or low emotional intensity (on a scale ranging from 1 to 5 ).

A coding table based on grids indexed to the criteria made it possible to standardize the measure of conflict intensity of each quote between cases and to obtain for each citation a conflict intensity value ranging from 2 to 10 .

Each contribution to the debates was coded a second time with one, and only one, opinion (positive or negative) of the actor in relation to a list of statements harmonized between the three cases (see Table 2) and designed to cover each measurement point (see Figure 4). We have thus built up a database for each case with 325, 545 and 285 opinions respectively.

Of all the maps in our atlas, we are publishing three that illustrate more specifically the dynamic link between governance rules and conflict handling styles.

\section{Part 3: Overview of the Cases}

Table 3 presents each organization, their Rahim's style at the beginning of the 
observation period, and the exposure to the risk of governance breakdown according to the criteria of Ostrom (1990: p. 194).

\subsection{The Associative School Case}

The predominant style of conflict revealed by one-third of the employees interviewed was the accommodating style: in the event of a conflict, the predominant attitude was to refuse to impose one's point of view upfront, but to talk privately about it with several people, except the member involved in the conflict. The

Table 2. Statements used for the coding of each quote.

\begin{tabular}{ll}
\hline Group of statements & Each quote is coded “Agree" or "Disagree" with one of the statements below \\
\hline Statements related to collegiality & We work in a collegial manner \\
At work, we share a common cause \\
governance & Governance is collegial \\
Statements related to conflict & Management has a clear idea of the organization's objectives and knows how to achieve them \\
handling style & In debates, the other's interest takes precedence over my own interest... \\
\hline
\end{tabular}

Table 3. Synoptic view of the partnership governance organizations studied.

\begin{tabular}{|c|c|c|c|}
\hline & School & NGO & Think Tank \\
\hline Activity & Education & Humanitarian & Advocacy \\
\hline Staff & 30 employees & 40 employees & 40 employees \\
\hline Location & One site in France & One site in France & One site in France \\
\hline & \multicolumn{3}{|l|}{ Organizational Culture Measure } \\
\hline $\begin{array}{l}\text { Initial action research } \\
\text { common to all three cases }\end{array}$ & \multicolumn{3}{|c|}{$\begin{array}{l}\text { Recording of debates and conflicts: interview of one third of the employees, directors, } \\
\text { staff representatives, Board of Directors }\end{array}$} \\
\hline $\begin{array}{l}\text { Conflict management style } \\
\text { at the beginning of the study }\end{array}$ & Mostly accommodating style & Mostly dominating style & Mostly avoiding style \\
\hline $\begin{array}{l}\text { Ostrom's Design Principle: } \\
\text { Distribution of costs is } \\
\text { proportional to distribution } \\
\text { of benefits }\end{array}$ & $\begin{array}{l}\text { No: No possible appeal of } \\
\text { decisions }\end{array}$ & $\begin{array}{l}\text { No: working conditions } \\
\text { negotiated on a case-by-case basis } \\
\text { between each employee and } \\
\text { management }\end{array}$ & $\begin{array}{l}\text { No: decisions by management } \\
\text { on a case-by-case basis and } \\
\text { without debate with the } \\
\text { employee }\end{array}$ \\
\hline $\begin{array}{l}\text { Ostrom's Design Principle: } \\
\text { Self-consciously change the } \\
\text { rules in a collective choice } \\
\text { setting }\end{array}$ & $\begin{array}{l}\text { No: Management decisions } \\
\text { imposed without debate via } \\
\text { formal written procedures }\end{array}$ & $\begin{array}{l}\text { Yes: Access to collective } \\
\text { bargaining arenas, but not very } \\
\text { effective in producing collective } \\
\text { rules that are binding on } \\
\text { everyone }\end{array}$ & $\begin{array}{l}\text { Yes: Access to collective } \\
\text { bargaining arenas, but } \\
\text { employees do not wish to join } \\
\text { collective debates }\end{array}$ \\
\hline $\begin{array}{l}\text { High risk on partnership } \\
\text { governance }\end{array}$ & $\begin{array}{l}\text { The collective project } \\
\text { becomes the project of just } \\
\text { one person }\end{array}$ & $\begin{array}{l}\text { Each individual tries to } \\
\text { optimize his or her interest }\end{array}$ & $\begin{array}{l}\text { Fragmentation of collective } \\
\text { identity }\end{array}$ \\
\hline $\begin{array}{l}\text { Action level of the } \\
\text { researcher }\end{array}$ & \multicolumn{3}{|c|}{$\begin{array}{l}\text { Access to governance and to all teams } \\
\text { Capacity of action interactions level (mediation) and collective rules level. Observation over several } \\
\text { years (from } 2 \text { to } 5 \text { years) }\end{array}$} \\
\hline
\end{tabular}


sustainability of the organization with partnership governance was at risk due to the development of resentment among members towards decisions taken alone by the elected Executive Director. The researcher presented his diagnosis to the executive director and the board of directors. The Executive Director resigned from his position two weeks later for health reasons.

Our objective shared with the governance team was to evolve from an accommodating style of conflict management to a compromising style through direct confrontation. Less than a month after a first mediation, the level of conflict did not decrease within the organization and the style remained very indirect. Following a disputed assignment of teachers between schools, an employee sent her complaints to the Board of Directors. The Board asked the researcher to work out a set of rules with the members in conflict. The purpose of the coordination protocol was to record very precisely the rights of each member of the partnership governance on the conduct of business and the decision-making process in the organization. The conflictual nature of the debates then diminished, and we did not observe any new conflict flare-ups during the following year.

\subsection{The NGO Case}

The predominant style of conflict following the interview of a third of these employees was the "dominant" style: in the event of conflict with a third party, the predominant attitude was to ask for accommodations that are self-serving and only suit one's individual interests. The organisational culture of the NGO was characterised by a weak formalisation of internal procedures, frequent debates on management decisions and management's avoidance of any arguing of its decisions.

The management of the NGO agreed to formalize an HR procedure for establishing salaries, but the decisions on increases were taken without any debate or consultation by the members of the NGO's management. The employees collectively expressed their great dissatisfaction with the decision-making process of pay raises. We then observed five new interpersonal conflicts, with high conflict intensity levels, and one collective conflict. Thereafter, we proposed and implemented a new salary-setting procedure involving all front-line managers and employee representatives at the decision meeting. Five months after the introduction of this collegial procedure, a plenary meeting concluded that the new salary review process was satisfactory. At this time, we did observe new interpersonal disputes about other topics that salaries, but with an intensity of conflict that no longer reached the levels observed previously.

\subsection{The Think Tank Case}

The predominant style of conflict revealed by one-third of the employees interviewed was the "avoiding" and "accommodating" style: the predominant attitude observed was not to express one's views about the organisation in front of the 
third party or interfere in the choices of another colleague. The organization consisted of the juxtaposition of autonomous teams, each with one or two research projects. The HR and management rules were clear, but management was looking for ways to create a sense of belonging to and ownership of, a common structure or goal.

The risk of fragmentation of the collective project appeared when the project leaders collectively refused to take a stance on prioritizing the association's actions. The directors then explicitly gave their own arbitration between projects and let employees vote anonymously to decide which projects should be funded by the organization. The research team initiated a second symbolic action: the creation of a career committee, bringing together all the managers, which then imposed a collective debate, and then finally, provided prompt feedback of the committee's decisions directly to the employees. In the year that followed this operation, several fairly intense individual conflicts emerged, and thereafter, the intensity of conflict decreased in the final months of the observation study.

\section{Part 4: Research Results and Discussion}

We seek to understand how the theoretical work of Rahim (1983) and Ostrom (2010) fits together to interpret the comparison of the three case studies: School, NGO and Think Tank, and in particular, whether Ostrom's principles of collegial governance are derived from Rahim's effective management style, and vice versa.

The conflict atlas provides a joint visualization of the evolution over the entire observation period for the three organizations of: 1) quotes revealing the actors' opinions regarding the collegiality of the organization and its governance, and 2) quotes revealing the actors' opinions on the conflict management style (see Figure 5 and Figure 6). At the outset of the observation, none of the three organisations observed, followed all of Ostrom's ideal organisational principles (see Table 3). This translates into a perception of collegiality in each organization outside the top right-hand quadrant of Figure 5 characterised by a bad opinion about the collegial work or the governance rules. The risk of the disappearance of organizations with partnership governance is particularly vulnerable in the absence of these Ostrom design principles (Ostrom, 1990: p. 194). Under these conditions, our empirical analyses are consistent with Ostrom's work, and the leaders of these three organizations clearly perceived a major crisis within their organizations.

At the end of the observation period, each organisation had put into place collegial governance rules to regulate the sharing of resources (sharing of professors decided by a balanced debate between institutions in the School, collegial setting of salaries in the NGO and the sharing of budgets and career promotions in the Think Tank). These internal procedures offered the possibility for members to request changes to the rules. At the end of the assessment, opinions on the collegiality of functioning and governance converged in the top right quadrant of 


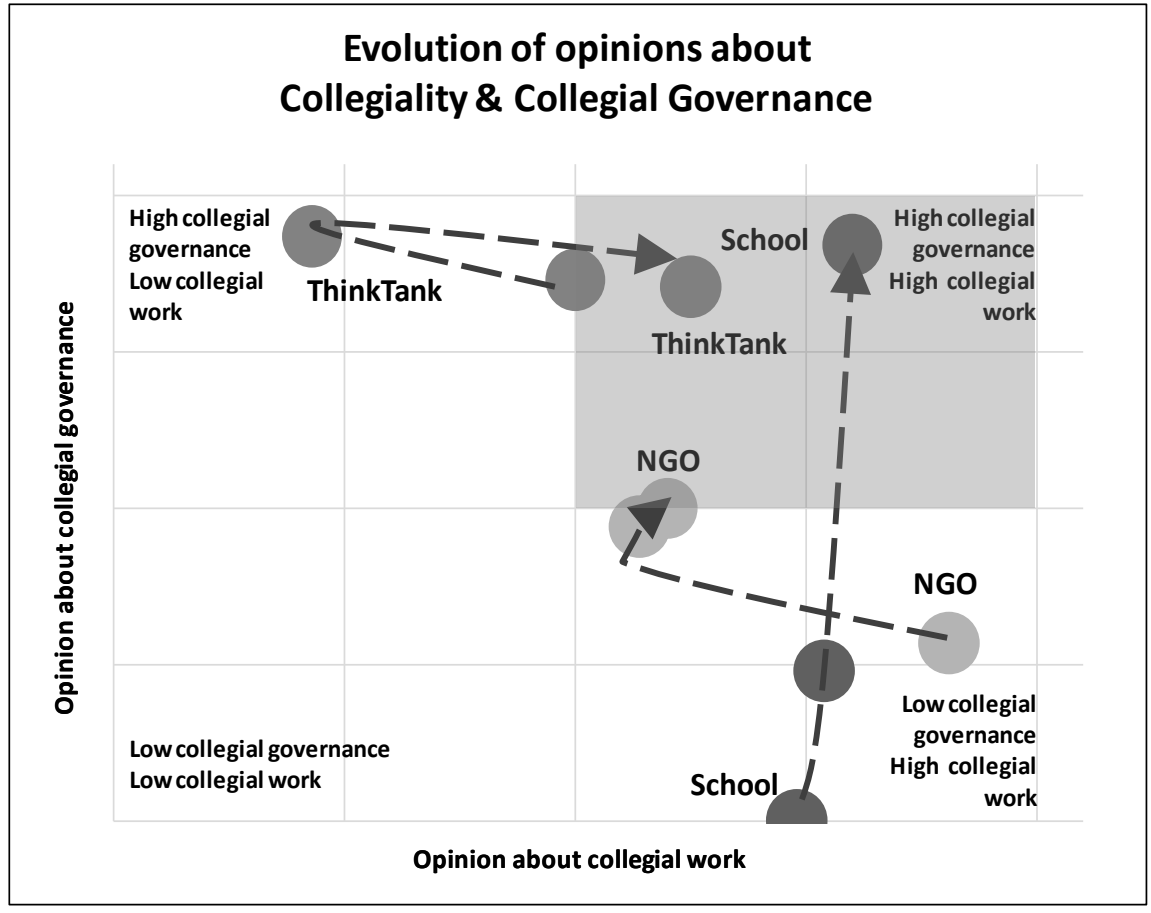

Figure 5. Evolution of opinions on the collegial nature of the functioning and governance of organizations. Source: from the onset to the end of the observation period.

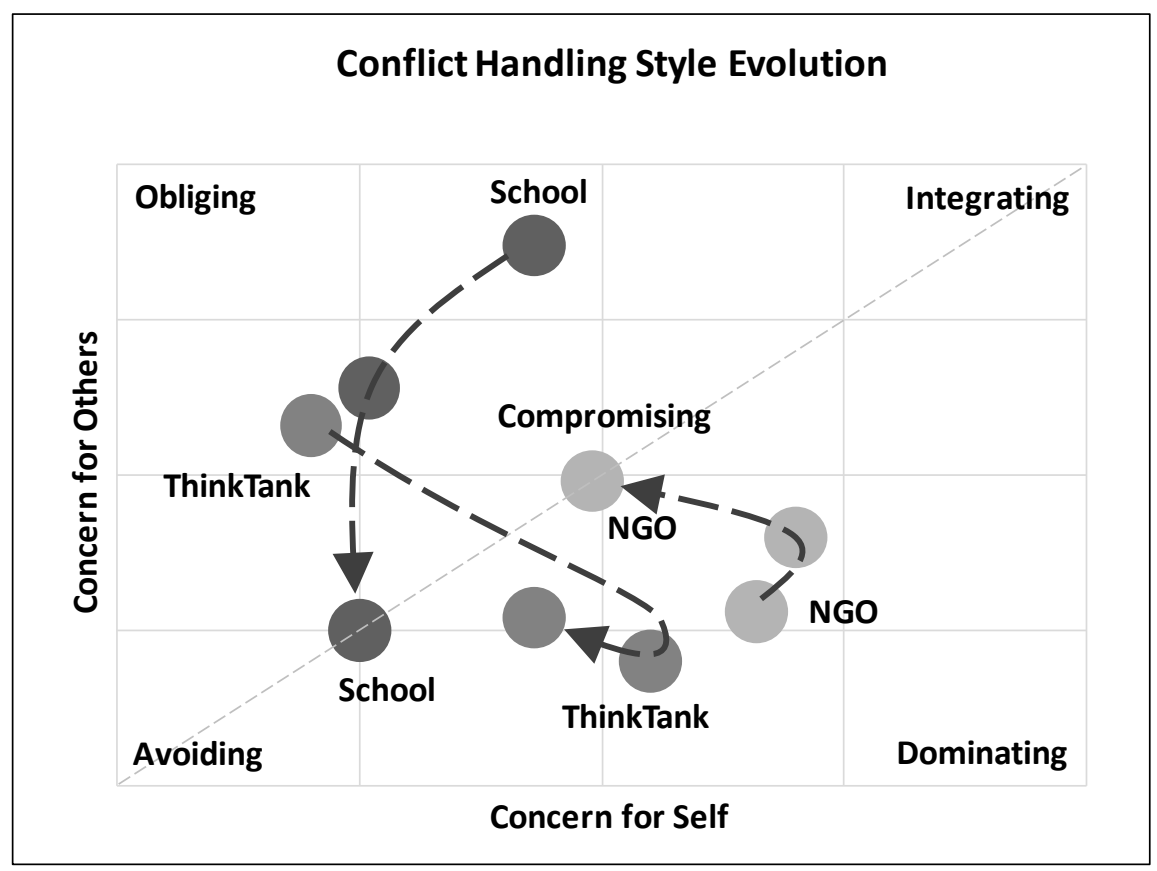

Figure 6. Evolution of each organization's conflict handling styles. Source: from the onset to the end of the observation period.

Figure 5, characterised by opinions globally consistent with the assertions describing collegial collaboration and governance (see Table 2). Initial attempts to resolve conflicts through simple mediation without changing the rules of collegiality in the NGO did not change the views on collegiality. In the Think Tank, a 
process of collegial decision-making on budgets without a platform for collegial discussion of resource sharing issues, worsened the perception of working collegially. In the NGO, the initial wage-setting procedure, without debate, decreased the perception of collegial governance, and in the end, the establishment of a collegial wage committee slightly improved this perception of collegial governance. The principle of collegial governance thus corresponds to the simultaneous establishment of an arena of collective arrangement and a mechanism for monitoring decisions.

Parallel to this evolution, and regardless of the style of conflict management at the start of the observation (accommodating for the School, dominating for the NGO and avoiding for the Think Tank), we observed an evolution of the conflict handling style towards compromise. This evolution is visible on the map of the conflict atlas in Figure 6, when each curve joins the diagonal of the figure, signifying a balance in the interests of the others and his or her own interests in conflict management. The style of compromise emerged after internal rules dictated that the interests of the other party had to be taken into account in key decisions on the running of the organisation. The style remained far from compromise, at the midpoint of the observation period, when internal procedures did not reflect Ostrom's rules of collegial governance.

The conflict atlas also makes it possible to reconstruct the evolution of the conflict intensity of the disputes within the members of the organisation with partnership governance (see Figure 7). We represent this evolution for each period characterised by a symbolic action on collegial governance. The intensity of conflict decreased significantly in the School following the establishment of the coordination protocol between its members. In the NGO, the level of conflict remained moderate ( 5 on a scale of 2 to 10), but the acute peaks of conflict observed at the beginning of the intervention ceased (levels 8 to 10 on a scale of 10). The level of conflict, initially fairly moderate, increased slightly within the Think Tank (characterized by the avoidance style at the beginning of observation), but then the intensity of the interpersonal conflicts decreased slightly at the end of observation. The final level of conflict intensity, nevertheless, remained in the mid-range of our measurement scale at the end of observation, consistent with the level of conflictuality observed in this type of organisation in other research studies.

Our observations revealed that the application of the Ostrom principle of resource sharing alone, without the collegial governance principle had increased conflict in all three organizations observed (see the midpoint of observation in Figure 7). On the other hand, the introduction of the collective rule-setting system had reduced conflict in the School and the Think Tank, and changed the style of compromise management in all three organizations. These results suggest that among the eight principles of Ostrom (1990), the principle of a collegial rule-setting arena has a very important impact on the sustainability of organisations with partnership governance, and can be considered as a determining principle in the stabilisation of these organisations. 

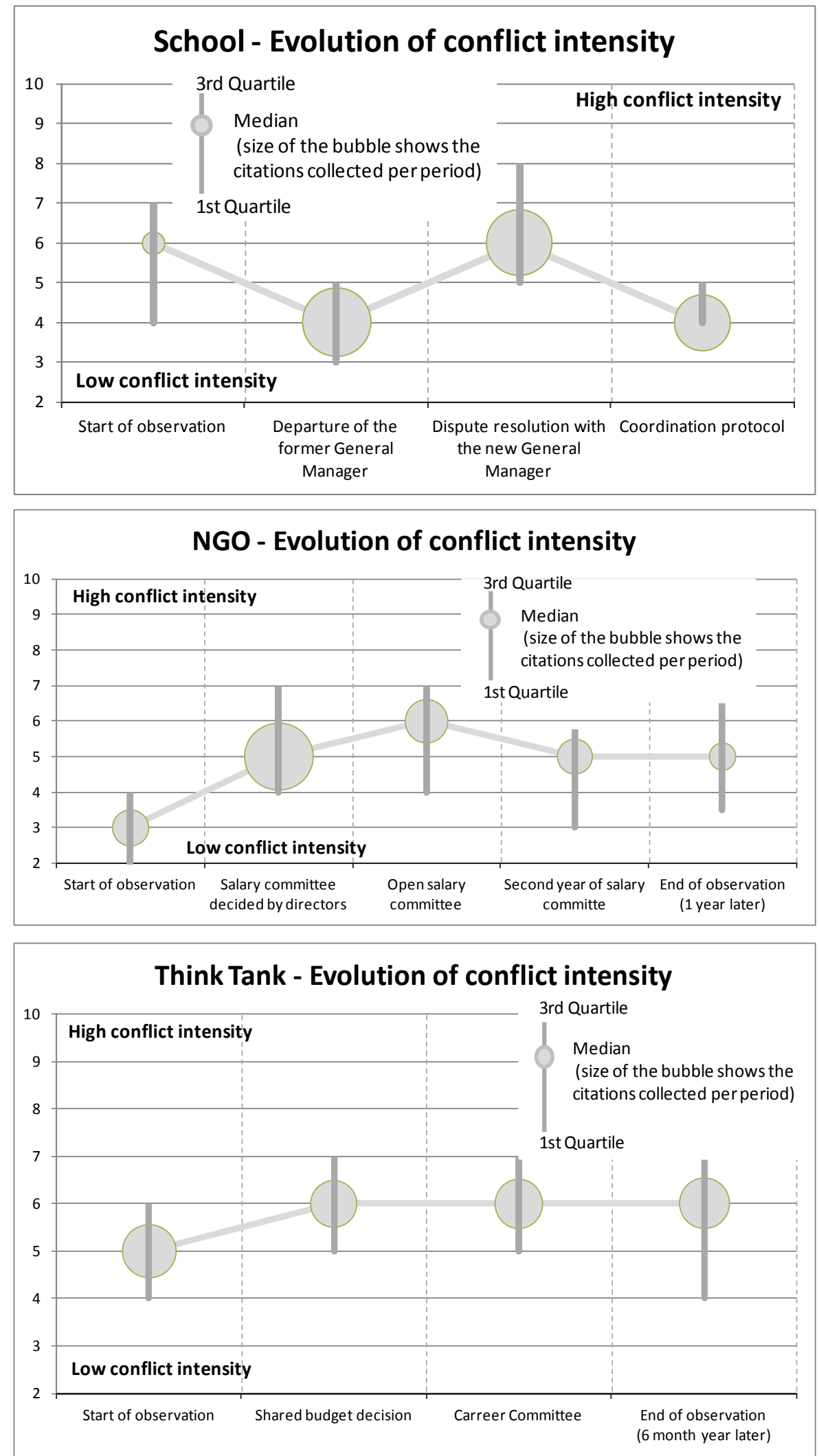

Figure 7. Evolution of the intensity of conflict in each organization according to symbolic acts of development of the collective rules of collegial decision-making. Source: from the onset to the end of the observation period. 


\section{Conclusion}

In each organization observed, the implementation of collegial governance rules (typically an arena for discussing collective choices to decide on the distribution of resources among members) has had several positive effects: the level of conflictuality has stabilized at a moderate level without dangerous spikes in intensity for the organization; the style of conflict management has evolved towards compromise, whereas it was initially ineffective (dominating, accommodating, avoiding); furthermore, this style of compromise has become a norm applied in other conflict situations.

Conversely, individual mediations or the introduction of a rule of resourcesharing without an arena for collective choice, have aggravated the situations: conflictuality has increased in the School and in the NGO; conflict handling styles have not evolved towards compromise in all organisations, and the perception of work collegiality ("we operate in a collegial manner") has clearly deteriorated in the NGO and in the Think Tank. This leads us to the suggestion that the establishment of an arena of collective choice is the major stabilizing principle among the eight principles of E. Ostrom, ahead of the principle of sharing resources among members.

Therefore, the rules of collegial governance exemplify well, in the three associations studied, as variables that directly affect the modes of conflict resolution of its members. This effect is amplified within the organization when the search for compromise becomes a norm widely adopted by members. Our observations highlight that when the compromise is enacted on a restricted issue (a rule on access to teachers in the School, on salaries in the NGO, on budgets in the Think Tank), then the compromise approach becomes a norm, and is also used in conflicts on other concerns (e.g., a budget sharing in the School, a negotiated departure in the NGO; a disengagement from a partner project in the Think Tank).

We can conclude from these observations that: 1) one principle among eight E. Ostrom's design principles, namely an arena of discussion of collective rules, stabilizes partnership governance organizations on a lasting basis; 2) the style of conflict handling through compromise is a hallmark of the effective collegiality of governance within this type of organization; and in contrast, 3) an inability to access an arena of collective choices, even if a rule otherwise distributes resources equitably, tends to increase the conflictual nature and the risk of destabilization of partnership governance organizations.

These results also open up opportunities for managerial recommendations in conflict resolution within organizations with partnership governance. Our research, therefore, suggests starting with an analysis that determines the conflict handling style in place and reveals the debates, particularly those related to issues of resource-sharing and collegiality that divide opinions in the organization. The manager will then be able to propose collective rules that will implement Ostrom's principle of collegial governance (this can be an action of collegial sharing of budgets, setting salaries, allocating resources on activities, etc...). 
However, at this point in the study, we are still lacking hindsight on the best methods for implementing collective rules that stabilize interactions between members of the governance on a long-term basis. The manager will then be able to define and adjust the collective rules until the emergence of a norm of conflict handling by compromise is reached, which will go hand in hand with a reduction in conflictuality.

These observations were collected from organizations with 40 employees. It would be beneficial to conduct further research in larger organizations with multiple subcultures, to study the interactions between subcultures and the styles of Rahim. In addition, complementary longitudinal studies could provide a better understanding of the link between the evolution of the rules of collegiality and the style of conflict handling at the level of each individual involved in the organization.

Beyond organizations with partnership governance, our research on the relationship between collegiality and conflict also opens up prospects for conflict resolution within the boards of directors of organizations with unitary governance, particularly startups. In these organizations, the board of directors often follows partnership governance rules (Blank, 2017), that are poorly understood by the founders, and many startups disappear as a result of internal conflicts within the governance team.

The first limit of this research deals with the managerial implications. Indeed, this article provides avenues for reflection and answers for managers and more generally for people in the HR function concerning how to manage conflicts in a non-profit company. It would be interesting to prolong the research in order to propose tools and procedures in conflict management approach for managers, and human resource support, if it is relevant.

The second limit of this research is found especially in the capacity to generalize the results of this research beyond the sphere of non-profit organizations with partnership governance. Is it possible to apply the same conflict resolution methods in private companies subject to stronger hierarchical arbitration?

\section{Conflicts of Interest}

The authors declare no conflicts of interest regarding the publication of this paper.

\section{References}

Blake, R. R., \& Mouton, J. S. (1964). Managerial Grid. Gulf.

Blank, S. (2017). When Founders Go Too Far. Harvard Business Review, November-December, 94-101.

Bommier, S., \& Renouard, C. (2018). L'entreprise comme commun. Charles Léopold Mayer.

Chatman, J. A., \& O'Reilly III, C. A. (2016). Paradigm Lost: Reinvigorating the Study of Organizational Culture. Research in Organizational Behavior, 36, 199-224.

https://doi.org/10.1016/j.riob.2016.11.004 
Coule, T. M. (2015). Nonprofit Governance and Accountability: Broadening the Theoretical Perspective. Nonprofit and Voluntary Sector Quarterly, 44, 75-97. https://doi.org/10.1177/0899764013503906

De Dreu, C. K. W. (2008). The Virtue and Vice of Workplace Conflict: Food for (Pessimistic) Thought. Journal of Organizational Behavior, 29, 5-18. https://doi.org/10.1002/job.474

Eisenhardt, K. M. (1989). Building Theories from Case Study Research. Academy of Management Review, 14, 532-550. https://doi.org/10.2307/258557

Galman, X. R. A., Galman, S. M. A., Cruz, J. B., \& Santos, M. D. (2021). The Relationship between the Conflicts and the Conflict Management Styles of Police Officers in the Philippines. Open Access Library Journal, 8, 1-10. https://doi.org/10.4236/oalib.1107540

Hardin, G. (1968). The Tragedy of the Commons. Science, 162, 1243-1248. https://doi.org/10.1126/science.162.3859.1243

Lubell, M. et al. (2019). The Origins of Conflict in Polycentric Governance Systems. In The Ostrom Workshop (WOW6) Conference (pp. 1-41). Indiana University.

Masters, M. F., \& Albright, R. R. (2002). The Complete Guide to Conflict Resolution in the Workplace. AMACOM.

Mayer, B. (2000). The Dynamics of Conflict Resolution. Jossey-Bass.

Ostrom, E. (1990). Governing the Commons - the Evolution of Institutions for Collective Action. Cambridge University Press. https://doi.org/10.1017/CBO9780511807763

Ostrom, E. (2010). Beyond Markets and States: Polycentric Governance of Complex Economic Systems. American Economic Review, 100, 641-672.

https://doi.org/10.1257/aer.100.3.641

Rahim, M. A. (1983). A Measure of Style Handling Interpersonal Conflict. Academy of Management Journal, 26, 368-376. https://doi.org/10.2307/255985

Teague, P., \& Roche, W. K. (2012). Line Managers and the Management of Workplace Conflict: Evidence from Ireland. Human Resource Management, 22, 235-251. https://doi.org/10.1111/j.1748-8583.2011.00171.x

Teague, P. et al. (2015). How Should Workplace Conflict Be Managed? Contrasting Pathways in the Literature (28 p.). Queen's University Belfast.

Ury, W. L., Brett, J. M., \& Goldberg, S. B. (1988). Getting Disputes Resolved: Designing Systems to Cut the Costs of Conflict. In Program on Negotiation at Harvard Law School (232 p.). Jossey-Bass.

Van de Vliert, E., Euwema, M. C., \& Huismans, S. E. (1995). Managing Conflict with a Subordinate or Superior: Effectiveness of Conglomerated Behavior. Journal of Applied Psychology, 80, 271-281. https://doi.org/10.1037/0021-9010.80.2.271

Venturini, T. et al. (2015). Designing Controversies and Their Publics. Design Issues, 31, 74-87. https://doi.org/10.1162/DESI_a_00340

Wall, J. A., \& Callister, R. R. (1995). Conflict and Its Management. Journal of Management, 21, 515-558. https://doi.org/10.1177/014920639502100306 